\title{
A (mis)guided adventure tourism experience: An autoethnographic analysis of mountaineering in Bolivia
}

\author{
Susan Houge Mackenzie* \& John H. Kerr
}

Due to the fast growing nature of the adventure tourism industry and the commodification of adventure activities therein, improved understanding of adventure tourism experiences and mountaineer adventure tourists in particular is needed. In an effort to move beyond traditional market segmentation approaches, this study analysed autoethnographical data from an adventure tourism mountaineering experience in Bolivia. This autoethnographic method facilitated a deeper understanding of mountaineering adventure tourism experiences and allowed for a multifaceted view of risk perceptions that has often been neglected in the literature. Data were analysed with a robust psychological framework (i.e. reversal theory) that was used to explain: (a) paradoxical desires for risk and safety in adventure tourism and (b) emotional and motivational fluctuations experienced by mountaineer adventure tourists. The importance of creating a 'protective frame' to ensure enjoyable experiences was identified, along with key factors that influenced this frame (e.g. guide behaviour, equipment, safety management procedures, other tourists, environmental conditions). Implications for adventure tourism practitioners are discussed, along with theoretical analyses. The utility of autoethnographic research in adventure settings, particularly in conjunction with established psychological theory, is highlighted and suggested as a fruitful avenue through which to enhance the adventure tourism discourse.

Keywords: tourism experience; adventure sport; mountaineering; ethnographic research; reversal theory; protective frames

\section{Introduction}

Adventure tourism is a fast growing industry worth more than $\$ 142$ billion, including airfare, equipment, and apparel (Xola Consulting, 2010). Research 
indicates that adventure tourists are affluent and educated, yet represent an underserved, dynamic, and growing market (Xola Consulting, 2010). Despite this growing market, research has not fully explored differences in adventure tourism experiences versus more traditional adventure recreation experiences. Commodification and commercial expediency, as well as unique participant motivations and expectations may produce adventure tourism experiences which are distinct from adventure recreation experiences. Scholars have highlighted the need for investigations linking adventure, sport, and tourism, and difficulties in finding 'data and quality case studies about individual sports tourism activities' (Hudson, 2003, p. xviii).

Previous research has generally treated adventure tourism as an extension of adventure recreation, and focused primarily on 'external' views of preconceived market segments and the physical risks inherent in adventure tourism (Weber, 2001). This literature has neglected the study of 'insider' views of adventure tourists' experiences and inherent differences in these experiences (compared with recreational adventure) due to the commercial nature of adventure tourism. Only a limited number of empirical studies have described adventure tourists' subjective experiences (Arnould et al., 1998; Gyimothy \& Mykletun, 2004), or explicitly investigated individual differences in risk perceptions due to previous experiences or predispositions (Weber, 2008). Moreover, studies which successfully capture the experiential qualities of adventure experiences often lack a clear theoretical framework to explain findings (e.g. Loeffler, 2004). Weber (2001) argued that individuals' subjective adventure tourism experiences may be inconsistent with traditional research classifications, and that more research should investigate psychological aspects of adventure tourism; how these psychological experiences are managed within adventure tourism; and the impact of these management strategies on experience quality.

\section{Theoretical Models of Adventure}

Adventure literature that has explored experience quality tends to highlight the positive outcomes of adventure, such as 'extraordinary experiences' (Arnould \& Price, 1993) that promote positive outcomes of fun, excitement, 'flow' or 'peak experiences' (e.g. Martin \& Priest, 1986), and profound journeys of self-discovery and insight (e.g. Walle, 1997). The ability to 'drop out' or escape from routinised life via 'edgework' (e.g. high-risk adventure) activities has also been cited as both a motivation for, and benefit of, adventure participation (Lyng, 1990). Adventure activities have been identified as ideal for facilitating optimal states such as flow, as these pursuits offer opportunities to exercise personal control over risks and to perform freely chosen, challenging activities (e.g. Csikszentmihalyi \& Csikszentmihalyi, 1990). Psychological adventure recreation models posit that participants continually seek feelings of competence, gained through experience and the accurate matching of individual aptitudes with challenge opportunities (Ewert \& Hollenhorst, 1989). Patterson (2002) also identified the importance of marketing these positive experiences to potential adventure tourists. However, studies which describe and explain potentially negative aspects 
of adventure experiences are lacking (Bentley \& Page, 2001; Davis-Berman \& Berman, 2002) and research has yet to assess whether adventure recreation models of experience and motivation apply to adventure tourism.

The Adventure Experience Paradigm (AEP; Martin \& Priest, 1986) is a psychological model which was proposed to explain optimal and non-optimal states in adventure pursuits. This model integrates concepts from flow theory (Csikszentmihalyi, 1975), optimal arousal theory (Ellis, 1973), and Mortlock's (1984) adventure stages. Although tests of the AEP's ecological validity supported its descriptive validity (e.g. Priest \& Carpenter, 1993), the AEP lacks empirical support for its predictive validity. An investigation of the convergent validity and predictive value of the AEP and flow models amongst whitewater kayakers found that neither the AEP nor the four channel flow model were statistically powerful in explaining the optimal experience construct in an adventure context (Jones et al., 2003). It is also noteworthy that the AEP, and the psychological models which inform it, are based on adventure recreation rather than adventure tourism settings. In adventure recreation, positive outcomes appear to result from increased opportunities to experience develop personal skills, exercise personal control over risk, experience autonomy, and overcome high challenges. In adventure tourism, these same opportunities may be constrained by commercial expediency or management approaches. Thus, the psychological models traditionally used in adventure studies may not be directly applicable to adventure tourism contexts.

Research has identified psychological quandaries inherent in adventure tourism experiences, such as participants' paradoxical desires for risk and safety (e.g. Arnould et al., 1999; Holyfield, 1999; Holyfield et al., 2005). Researchers have postulated that adventure tourism can embody this paradox by 'hiding' one of two key elements from participants. Adventure tourism providers either increase risk perceptions while minimising 'actual' risk (Holyfield et al., 2005) or, conversely, minimise risk perceptions in activities with relatively high levels of 'actual' risk (Palmer, 2004). Fletcher (2010) characterised these situations as a 'public secret' (i.e. 'something that is generally known but cannot generally be articulated'; Taussig, 1998, p. 246 cited in Fletcher, 2010) that allows adventure tourists to simultaneously accept the contradictory notions that they are safe and in danger. Although this research provides sociological explanations of tourists' risk perceptions, a fuller account of the psychological mechanisms underpinning tourists' seemingly 'paradoxical' experiences and motivations in adventure settings is merited.

\section{Reversal Theory Links to Adventure Tourism}

Adventure is characterised by unknown dangers or risks, which entail uncertain outcomes for participants (Merriam-Webster, 1994). Adventure can be experienced across any domain in which risk and uncertainty are present, such as in personal relationships or financial investments. In these situations, the risks are generally social, emotional, or financial. Adventure tourism and adventure recreation represent two domains in which adventure can be characterised not only by physical risks (e.g. injury or death), but also social (e.g. humiliation) and emotional (e.g. fear, anxiety) risks. 
While the physical risks inherent in adventure tourism are presumably 'managed' by responsible adventure providers, adventure tourism poses additional risks (e.g. psychological) that may be (mis)managed, or overlooked entirely, by adventure tourism operators.

Although adventure recreation involves the deliberate seeking of danger or risk (Ewert \& Hollenhorst, 1989), research indicates that adventure tourists only seek the perception of risk to the extent that they feel simultaneously protected from various forms of risk by operators (e.g. Cloke \& Perkins, 2002). Thus, adventure tourism, which 'sells' risk-taking experiences, is best understood within a framework which adequately accounts for this paradox. Reversal theory (e.g. Apter, 1982, 2001) is a general psychological model that describes the structure of subjective experiential states and offers a theoretical basis from which to understand seemingly paradoxical states and emotional fluctuations (e.g. relaxation, excitement, anxiety) in adventurous activities.

Reversal theorists identified that, particularly in adventure contexts, both high and low arousal can be experienced as pleasant or unpleasant (e.g. Apter, 1992). Although human behaviour often appears paradoxical and inconsistent, there are underlying structures (i.e. motivational states or 'frames of mind') which dictate these behaviours and cognitions (Apter, 1982). Reversal theory proposes four pairs of motivational states which influence subjective experience. Psychologically healthy individuals are able to alternatively satisfy opposing needs via regular reversals among the states described in Table 1 (Frey, 1999).

Reversal theory was generated as an alternative to optimal arousal models often used in adventure studies which posit that humans have a single stable 'optimal' point around which they prefer to function (e.g. Martin \& Priest, 1986). Specifically, reversal theorists highlighted differential interpretations of high arousal during adventure activities (i.e. anxiety or excitement) as being insufficiently accounted for in optimal arousal models (Apter, 1992). Evidence from clinical case histories, phenomenological, psychometric, experimental, and psychophysiological studies were influential in the formation and validation of reversal theory (see Apter, 1992, 2001 for review), which has since been developed across a range of disciplines including sport and recreation (e.g. Kerr, 2001, 2007). More recently, reversal theory has been successfully applied to understand fluctuations in motivations and emotions in adventure recreation experiences with both experts and novices (Houge Mackenzie et al., 2011).

Reversal mechanisms. Apter (1982) proposed three mechanisms, or 'inducing agents', which precipitate reversals. One was internal or external contingent events

Table 1. Motivational state pairs in reversal theory

Telic: serious, outcome-oriented, arousal-avoidant Conformist: rule-abiding Mastery: domination-oriented Autic: self-focused, concern for self
Paratelic: playful, process-oriented, arousal-seeking Negativistic: rebellious Sympathy: relationship-oriented Alloic: other-focused, concern for others 
(e.g. falling into the water while whitewater rafting). Another was frustration, which occurs when a goal or activity cannot be completed or enjoyed (e.g. inability to summit a mountain due to poor weather). Satiation, due to remaining in one state for an extended period (e.g. experiencing heightened arousal for several days while participating in an adventure race), could also trigger a reversal. Typical adventure experiences have been cited to support these conjectures. Misadventure (contingent event) or satiation during exciting, high-arousal adventure experiences can induce reversals to a serious, arousal-avoidant (telic) state. If arousal levels remain high despite this decrease in preferred arousal (due to state changes), anxiety is expected to ensue (Apter, 2001).

\section{Paratelic Protective Frames: The Essence of Adventure Tourism?}

Of perhaps greatest relevance to the current investigation is reversal theory's concept of the protective frame. This concept developed from a diverse range of case studies, many of which focused on differences in traditional sport versus 'high-risk' sport experiences (see Apter, 1992, and Kerr, 1999, for review). For example, risk sport participants (e.g. downhill skiing, motor racing, surfing) were more likely to endorse playful, arousal-seeking (paratelic) motivations, whereas safe sport participants (e.g. golf, bowling) were more likely to endorse serious, arousal-avoidant (telic) motivations (Kerr, 1991). These studies further revealed how emotions accompanying heightened physiological arousal levels differed greatly depending on individual's subjective interpretation of the situation. High arousal could be experienced as either excitement (a 'good arousal') or anxiety (a 'bad arousal') depending on people's psychological frame of mind (Apter, 1992, p. 14).

As the name implies, a 'protective frame' provides feelings of protection from risk or danger and is generally operationalised as confidence in oneself, others, and/or equipment (Apter, 1993). When the protective frame is active, heightened arousal and challenges associated with risk are experienced as exciting; thus, the presence of a protective frame characterises a playful (paratelic) state. When the protective frame is lacking, a serious (telic) state ensues wherein heightened arousal is experienced as anxiety. A useful metaphor for conceptualising the protective frame is that of viewing a tiger enclosed in a cage (Apter, 1992). This situation is generally exciting as the element of danger (the tiger) is coupled with an element of protection (the cage). Conversely, the absence of a tiger (i.e. risk or danger) would likely be boring, just as the absence of a cage (i.e. protection) would generally incite fear. Thus, excitement (pleasant heightened arousal) is only possible when risk is coupled with some form of protection. Reversal theorists postulate that a strong, resilient protective frame is fundamental to exciting, playful (paratelic) experiences (Apter, 1992, 1993). Without protection, risk-taking is experienced as anxiety and fear; within this protective psychological bubble, it feels exciting.

Adventure tourism appears to operate on this paradox. Participants voluntarily seek what they perceive to be 'risky' activities, to the extent that they feel protected from risk. As adventure tourists have reported seeking fear and thrills with minimal exposure to actual risk, successful adventure operators are able to reduce actual risk while 'effectively 
commodifying the thrills within' (Cater, 2006, p. 317). From this perspective, the protective frame, and the notion of risk which is not risk, could perhaps be considered the essential element or key 'selling point' of successful adventure tourism operators. Therefore, fostering a protective frame via professional guiding and equipment is expected to be an essential ingredient in delivering successful adventure tourism experiences.

\section{Mountaineering Adventure Tourism}

The literature review has identified that tourism and recreation converge in adventure settings, and that theories used to explain adventure tourism require further development with regard to understanding: participants' subjective experiences; the possible psychological risks associated with adventure tourism; and the paradoxical nature of adventure tourism. The importance of developing quality case studies of specific sport tourism activities (Hudson, 2003) and investigating mountaineering tourists' experiences prospectively (Pomfret, 2006) has also been recognised. Mountaineering has long been considered a recreational adventure activity; however, the growth in adventure tourism has led to increases in mountaineering adventure tourism offerings, many of which require minimal, or decreased, participant skills. Pomfret (2006) recently highlighted the need to extend our understanding of mountaineers in an adventure tourism context. As researchers have limited understanding of mountaineering adventure tourists, investigations are needed to establish whether fundamental differences between mountaineer adventure tourists and mountaineer adventure recreationists exist. In the current study, a prospective, autoethnographic approach was used to highlight motivational and emotional patterns experienced during mountaineering adventure tourism, which may differ from motivational or emotional patterns experienced during mountaineering adventure recreation.

The purpose of this study was to provide an autoethnographic perspective on mountaineering adventure tourists' experiences which employed an established psychological framework to strengthen data analysis. Specifically, this case study examined an experience in which motivational reversals occurred and the implications of these psychological fluctuations for the tourist client and adventure company. While reversal theory constructs have been previously described and compared with conceptual frameworks in tourism literature (Gyimothy \& Mykletun, 2004), we are unaware of research that has explicitly used reversal theory as the primary basis to explain tourism experiences in general, or mountaineering adventure tourism experiences in particular. This article sought to account for the paradoxical and dynamic nature of these experiences by interpreting autoethnographical data through a reversal theory lens, and thereby identifying governing psychological processes.

The autoethnographical data presented in this study were recorded during a trip to South America (2010) to engage in a particular subset of sport tourism: mountaineering adventure tourism. It details portions of a powerful experience which occurred when I, the lead author, participated as a mountaineering adventure tourist in a guided group climb of Huayna Potosi near La Paz, Bolivia. This approach was used to uncover specific factors that had a direct, and often negative, effect on my 
perceptions, emotions, motivation, behaviour, and satisfaction, and the psychological processes underpinning these experiences. This study sought to address identified knowledge gaps and augment sport tourism literature by contributing:

(1) A study focused on subjective adventure tourism experiences and their impact on overall experience quality;

(2) A coherent theoretical account of the psychological mechanisms underpinning subjective adventure tourism experiences;

(3) A quality, prospective study of mountaineering adventure tourism;

(4) An alternative explanation of how adventure tourism can (un)successfully embody the paradox between perceived risk and security; and

(5) An emergent methodological approach (autoethnography) and innovative theoretical framework (reversal theory) which may guide future investigations and enrich adventure tourism discourse.

\section{Method}

Qualitative research methods have been identified as 'essential' to fully understand adventure tourism experiences (Weber, 2001). Autoethnography in particular has been cited as a methodology with 'considerable untapped opportunity' to explain leisure activities (Anderson \& Austin, 2012, p. 131). This approach has been used successfully to describe a range of sport and tourism experiences, such as mountain guiding (Beedie, 2003), triathlons (Kidder, 2006), rollerblading (Kahn, 2009), and whitewater rafting (Jonas et al., 2003).

Two distinct autoethnographic approaches have been recognised: evocative and analytical autoethnography (Anderson \& Austin, 2012). Evocative autoethnographers stimulate emotional empathy and perspective taking in via evocative communication techniques, whereas analytical autoethnographers employ traditional theoretical and conceptual analyses that align with social science epistemologies (Snow et al., 2003). The common feature in these approaches is the recognition of the researcher's self as central to the ethnographic investigation (Anderson \& Austin, 2012). The current study draws upon evocative autoethnography techniques to facilitate emotional identification with the participant's experiences, while conceptually analysing data through an established theoretical lens. It was hoped that this approach would allow readers to empathise with the authentic emotions conveyed and thereby gain a more intuitive understanding of the theoretical framework presented. The method used in this study satisfied Anderson's (2006) five key autoethnographic features, namely: complete member status of researcher; analytic reflexivity; narrative visibility of the researcher's self; dialogue with informants beyond the self; and commitment to theoretical analysis.

\section{The Researcher as an Experienced Participant Observer}

Qualitative data analysis is dependent on the extent to which an investigator establishes sufficient credibility and trustworthiness. Therefore, a 'thick 
description' of the primary researcher, data collection, and procedures is reported in detail. Data collection was undertaken when I, the first author, entered the role of a tourist client and participant observer in an adventure sport activity that was largely unfamiliar to me. At the time, I had 10 years of experience as a guide or participant across a range of adventure sports (e.g. river surfing; rafting; mountain biking; adventure racing), and a background in psychological research, adventure tourism management, and Spanish language. This study sought to convey an authentic and emotionally nuanced account of my mountaineering adventure tourism experience, while viewing that entire experience through a critical lens.

\section{Setting the Scene, Data Collection, and Analysis}

Data were collected during a 3-day guided climb of Huayna Potosi (Bolivia, November 2010). Although Huayna Potosi rises just shy of 20,000 feet, it is touted as an 'easy' climb among mountaineers (e.g. Huayna Potosi: SummitPost, n.d.) and 'the easiest "6000 [meter] er" in the world' (Huayna Potosí, n.d., para 1). As such, it attracts novice tourists with little or no mountaineering experience, such as the group detailed in this study. Our climbing group consisted of: Scott, ${ }^{1}$ the first author's close friend; Sally and Fred, recent acquaintances; Mike, an independent traveller; Jose and Julio, the primary guides; and Rocky, a guide who arrived late on Day 2.

Data consisted of diary entries, experiential diagrams, emails, and field notes from conversations with fellow tourists. The 'experiential diagrams' were a spontaneous strategy developed by the lead author to visually represent key emotional changes and factors contributing to psychological reversals throughout the trip. They resembled a flow diagram or chart of her current mental state (e.g. 'high' ascending lines $=$ positive mood; 'low' descending lines $=$ negative mood) coupled with field notes. Textual analysis of these data was conducted by identifying key themes relating to influences on emotional states. Raw quotes associated with a particular part of the trip (e.g. Day 2, evening) were grouped together within the experiential diagram and pursued for distinct themes. Repetitious themes were identified in each data source along with themes related to reversal theory constructs (e.g. motivational states, reversals, protective frames). The metamotivational state coding schedule was also used to guide data coding (O'Connell et al., 1991). Multiple data sources were used to triangulate and verify the consistency of interpretations, while integration of data within a visual diagram clarified how this experience unfolded in relation to state changes (positive or negative) and any pertinent reversal theory constructs.

The second author, who was experienced in qualitative research and an expert in reversal theory, substantiated the lead author's analyses by carefully reviewing all data sources and independently identifying common themes. He then compared his analyses with the lead author's analyses and any discrepancies or inconsistencies were discussed and reconciled. The second author did not identify any misrepresentations of the data. 


\section{Results and Discussion}

In this section, the raw data are presented in chronological order, beginning with pretrip impressions and followed by representative narratives of each trip day (i.e. Day 1, Day 2, Day 3). Following the presentation of data, it is interpreted and discussed in greater depth. Autoethnographical data excerpts appear in italics followed by the data source in brackets (e.g. email, diary, experiential diagram).

\section{Pre-trip Impressions and Expectations}

On the day prior to embarking, Scott, Fred, Sally, and I met with the mountaineering company owner who inspired us with confidence due to: the reputation of this company (e.g. there were many official-looking documents on his walls); his command of English; his background as a medical doctor; and his questioning of our medical histories and subsequent examinations (e.g. scrutinising blood vessels in our eyes). I felt, he exhibited a prudent approach to risk management in his client screening process and projected an image of competence as a physician and mountaineer. His expertise, humour, and thorough responses created a sense of trust and confidence that convinced us to register for the trip. Based on this initial encounter, and our lack of recreational and tourism mountaineering experiences, we expected a physically challenging experience in a beautiful natural setting that was well-organised and ultimately safe and enjoyable. We assumed that all risks would be clearly communicated and that specific strategies (e.g. what to do in an avalanche or how to cross a crevasse), sufficient training, equipment, and supervision would be provided. However, these expectations quickly began to unravel, as evidenced in data presented below.

Day 1: Gear Allocation, Travel to Mountain, Climbing Training, and Evening Socialisation

The first day was a lesson in disorganization as the owner... took us to different sites to get our gear, all of which seemed to be broken or in some state of disrepair. Jackets did not have zippers; the pants were too small, etc... After much trying on of different gear and swapping around and fixing things, we got very frustrated. [Email]

I thought [the owner] was alright to start with, and then I realised he was just after the money. He was a prick. He didn't have any gear. [Scott]

While driving through traffic into middle of La Paz the driver seemed clueless - no idea where our hostel was. We had to make two separate gear stops ... it seemed disorganized and unnecessary. The guides/owner didn't care that the gear didn't fit right or was broken. No communication between the owner/staff and clients - no one seemed to know what was going on. Guides only spoke Spanish, so I had to translate for everyone. I was also playing peacekeeper/ mediator between [Scott], who was getting angry at the lack of organization/ assistance/poor gear, and at the guides/owner. [Experiential diagram notes]

Once the gear was sorted the real adventure began. We drove to the base and commenced three hours of climbing training with ice axes, crampons, the lot, on the glacier face. Not only was this our first time using this gear, but we were the only group not given helmets and all the instructions, of which there were so few... were in Spanish. OK for me, but not so much for the rest of the group which spoke little or no 
Spanish. When we questioned the wisdom of not distributing helmets for ice climbing, we were greeted with laughs and told that our guides were professionals! Ha! As though this meant we couldn't get hurt. This reassurance ... instilled unshakable confidence amongst us [sarcasm]. [Diary]

In the end, we actually enjoyed practicing together, walking like ducks and other animals, and pretending to 'save' ourselves with ice axes as we hurled ourselves down small ice sheets... We returned for an amazing dinner in front of an open fire. Possibly my favourite part of the trip. [Diary]

I wasn't really too worried about [the lack of helmets] at that stage... I enjoyed it. [Scott]

Felt more confident after practicing skills - using crampons/ice axes. Felt more acclimatized after I digested ...lunch. Much improved attitudes in whole group in the second half of training and on the way down from training. Great meal; nice warm fire. People were happy, sharing stories/socializing/feeling well fed and relaxed - except for Fred (sick). I wanted to look after him (alloic/sympathy states). Some nice interactions with the hut staff/locals - we learned about them and their history. I still sensed some apprehension in the chatter/nervous laughter amongst the group. [Experiential diagram]

\section{Day 2: Ascent to High Base Camp}

I had a lazy, relaxing morning, ate loads more food. At midday we finally started the trek to high base camp [5,200 meters]. This went well aside from the...pack I was carrying which reduced me to hands and knees climbing in many spots. By this time I had managed to [convince] the guides [to give] us all helmets, so at least that was a relief ... Three of us were OK with the altitude but [Fred and Mike] were really struggling. It was annoying to keep waiting for them. [Diary]

Good, huge breakfast. Feeling good. Still nervous about the climb, but it's a clear, sunny day. I can see the mountain so that gives me more confidence. Good/improving rapport with guides - this helps my confidence/protective frame. Good team spirit in group - we all wanted to help out and encourage Fred. Excited to go up, but still nervous about climbing in ice/snow/altitude. Reversals I noticed: alloic [other-focused] when eating together and resting; autic [self-focused] when walking and working hard/ feeling unwell. Example: I wanted to look after Fred in the morning, but when I am struggling [later in the day] I feel annoyed with the others easily (autic). [Experiential diagram]

Top base camp was very basic, just 5 or 10 mattresses in a tin shack, but great views. No one wanted to eat anything, but we forced down some soup and were told to try and sleep until 12 am when the real climb started ... I would not recommend trying to sleep at 5,200 meters [17,000 feet] if you have not had the pleasure yet! You will not sleep but rather become more and more nauseous and your head will feel like it is steadily inflating to bursting. (If you are real nana like me, you will probably start to weep a bit ... [out of] pure self-pity...). [Diary]

I was fine until I lay down. Then my head felt like it was going to explode. [Scott]

\section{Day 3: Final Ascent and Return to Low Base Camp}

At 12 am I wake at 5,200 meters [17,060 feet] and stumble around feeling like I want to vomit, diarrhea or simply die, maybe not in that order. [Mike] decides he will not even attempt the summit (this from the man who climbed Kilimanjaro). I finally get my gear on and by that time ... [Fred and Sally] have gone with one guide each. Our guide, Rocky, who only arrived late yesterday and we hardly know tells me and Scott (who can't understand Spanish)... to get our crampons on. Rocky is shocked and appalled that we have no clue in this department (we have only used crampons once before) and then ropes us up with no instructions other than to hurry up and hold the 
rope in one hand, ice axe in the other. Then we are off into the great darkness looming ahead. As we walk my apprehension grows ... with every step I hear snapping, cracking and popping...

Unfortunately my knowledge of risk management and outdoor activities gave me enough information to scare the crap out of me, but not nearly enough skills to feel confident that I could keep myself safe (Rocky didn't seem too concerned with safety in general- he even questioned my 'unnecessary' decision to wear a helmet). I frequently asked him whether the ice was stable, only to be asked: how much to you both weigh? And then told we were heavy. Great. This did not bode well with me. He also neglected to alert us when we were crossing many of the crevasses which littered the walk up to the summit and only spoke to us to complain at how slowly we were walking, even though Scott's crampons didn't fit and kept falling off. Rocky then asked why we had these crampons as they were too 'technical' for us. Of course, it was his company that gave us this equipment. To top it off, Scott's helmet broke half way up and that, combined with his poor headlight, no Spanish, and altitude sickness, meant he was literally getting dragged up the mountain behind me without any real idea what lay ahead... [Scott] moved really slow and kept pulling back on my rope when I was jumping crevasses - it was driving me crazy and scaring the crap out of me as he didn't seem to have a clue!...

To cut a terrifying story short, we got up to a point where we had to jump a large crevasse and climb up a vertical wall before the sun came up. So much for a 'beginners' mountain hike. Although physically I was holding up, Scott's heart was hammering out of his chest and he could only go 10 feet without stopping. Whereas my trouble was the sheer terror I felt at being stuck on what appeared to be unstable ice and snow, roped up to an incompetent guide who [could not care less about] our safety, or instructing us on what to do in the event that we fell down a wall, there was an avalanche, or a crevasse opened up beneath us. I think Rocky said it was all just 'parte de la adventura' [part of the adventure] at one point. What a legend [sarcasm].

All but one of our group decided at 5,800 meters [19,029 feet] to turn back just shy of the summit. I got roped to our lead guide with my petite friend Sally, which came as a huge relief due to our combined weights. As we stopped to watch the sun rise over Bolivia...Scott heard the sound of a train roaring down the mountain, which turned out to be an avalanche! He told us to get to the side, while our two guides just started laughing. They said it was too far up to reach us. How reassuring [sarcasm]. Now all I wanted to do was get the hell off that mountain and spent the next few hours trying to put one crampon in front of the other and quelling the rising panic I felt every time we jumped a crevasse or the ice popped. At two points Sally actually slid down sheer ice faces and we had to dig in to break her fall... (she is light thank god)...When we got back to base all we wanted to do was either vomit or release the pressure in our heads, so we had a rest and then stumbled back down ... for a few more hours. [Email]

All the way up I had no protective frame ... I know enough about risk management to know their systems were not safe (e.g., no redundancy). I was serious (telic) pretty much the whole time due to lack of a protective frame: from guides, environment, equipment. Finally reversed once we got lower, back onto rock, and it was sunny out. [Experiential diagram notes]

We did Huayna Potosi but I didn't reach the top...It's too bad. In adventure tourism, success or failure is often measured by external achievements (i.e., did you summit?) rather than how you got there or your internal experiences or whether you made the right decisions... I think we did [make the right decision] considering ... my protective frame was non-existent by the time we turned around ... I was 
actually proud of my decision... because it was harder to decide to turn back than carry on. [Diary]

\section{Reversal Theory Interpretation of Key Themes}

As detailed in the methods section, textual analysis of the data was conducted by: grouping quotes chronologically within an experiential diagram; identifying influences on emotional states at various time intervals; coding motivational states; and identifying any emergent themes. For example, Jackets did not have zippers; the pants were too small...After much trying on of different gear and swapping around and fixing things, we got very frustrated, was coded as the telic state (no protective frame) and 'equipment'. Good team spirit in group - we all wanted to help out and encourage Fred was coded as the alloic-sympathy states and interactions with other participants'. Data analysis identified the following four key elements which influenced my experience (positively or negatively) and the salience of my 'protective frame': the guides, equipment, other participants, and the environment. General motivational state patterns also emerged. These factors are discussed below in relation to their practical and theoretical implications.

Guides. Interpersonal interactions with our guides emerged as the single most influential factor in determining overall experience quality. The guides' apparent lack of concern, organisation, and effective communication destroyed my confidence in their ability to protect me or my climbing partner (Scott). While these perceptions may have resulted from my euro-centric background and expectations of guided tours, their nonchalant approach greatly diminished my protective frame and activated a serious, arousal-avoidant (telic) state characterised by concern for myself over others (autic and mastery states) during the majority of our climbing time. This was demonstrated particularly on Days 1 and 3 (e.g. during gear fitting, on the final ascent) when our guide did not communicate hazards or climbing instructions. Conversely, when we were not climbing and had time to socialise with the guides (e.g. evening of Day 1), I reversed to the alloic (concern for others) and sympathy (relationship-oriented) states. At these times, I became more personally acquainted with our guides and felt affectionate, sociable, and interested in their personal histories.

My interpretations of the guides' behaviours largely determined whether I experienced the adventure as pleasant excitement (within a protective frame) or unpleasant anxiety (without a protective frame). While there were episodes in which I felt excited (paratelic; e.g. afternoon of Day 1), I remained in the latter category for the majority of this experience. It is also noteworthy that some secondary factors discussed below (i.e. equipment, environment) could have been potentially mitigated and transformed into a positive experience, had the guides addressed them in another way.

Equipment. A related, but distinct, factor which influenced my experience was the type and quality of equipment provided. The poor quality, or absence, of equipment was apparent from the first morning of the trip and had a negative impact on the overall experience. For example, helmets were not provided until our group insisted on wearing them, at which point they were borrowed from another tourist group. 
Poor equipment negatively influenced my experiences on a daily basis and almost prevented my climbing partner (to whom I was roped) from ascending on Day 3 (e.g. crampons falling off). These events further eroded my protective frame, through lack of confidence in the equipment and the guides who distributed it, and fostered unpleasant feelings of anxiety and frustration throughout the trip.

Other participants. Fellow clients played a lesser role than the guides in influencing my motivational states; however, there were instances in which my peers elicited strong emotions. For instance, feelings of playfulness and camaraderie developed during training (e.g. walking like ducks, self-arresting) and evening socialising on Day 1 (e.g. caring for Fred who had a stomach ailment). While ascending the mountain, however, Fred's sluggish pace became annoying as I preferred to walk at a faster pace without feeling 'stuck' behind someone (Day 2; telic, mastery states). I also felt anxious and frustrated by Scott and Sally's slow progress while we were roped together in these unstable conditions. Depending on my motivational state and protective frame (or lack thereof), other clients elicited feelings ranging from concern, caring, and affection to anxiety, frustration, and anger.

Environmental conditions. The physical environment influenced my motivational states both positively and negatively. Feeling warm, well-fed, and physically comfortable (e.g. evening of Day 1, morning of Day 2), facilitated the playful (paratelic), otherfocused (alloic), and relationship-oriented (sympathy) states discussed previously. However, the natural environment also diminished my sense of protection from danger (paratelic protective frame) while climbing. This was particularly evident on Day 3 when ice was cracking continuously and we travelled in darkness over crevasses. I realised that ice was shifting due to warmer conditions and that many groups were using the same trail which crossed obscured crevasses; however, my limited technical knowledge precluded a reasoned, accurate risk assessment. This increased my risk perceptions and diminished my protective frame. These conditions, coupled with my lack of understanding and witnessing of two avalanches on the descent, further contributed to my serious (telic), self-focused (autic) state. Notwithstanding these environmental trepidations, my confidence and positive interpretation of challenges (i.e. excitement due to a paratelic protective frame) could have been restored by a different guiding style. Had our guides changed their communication style, I might have reversed to playful (paratelic) state in which I relished the environmental challenges and achieved our goal of reaching the summit. By overtly demonstrating their expertise; using more frequent and informative communication; discussing hazards and safety techniques; and/or outwardly displaying genuine, caring behaviours towards their clients, the guides could have instilled confidence and facilitated an exciting and enjoyable climb in the face of obvious environmental dangers.

\section{Motivational State Fluctuations}

In summary, this experience was primarily characterised by the absence of a protective frame due to guiding styles, equipment, and the natural environment. The motivational states most commonly identified in this study were the telic (serious, 
outcome-oriented, arousal-avoidant), autic (self-focused), and mastery (dominationoriented) states. These were the states I generally remained in when climbing. Reversals to other-focused (alloic) and relationship-oriented (sympathy) states were primarily experienced while resting or during 'down time' when I could converse and share my experience with others, or assist struggling group members.

In contrast to my consistent state pattern, Sally appeared to exhibit a playful (paratelic) state throughout our climbing activities. She even remained unfazed after falling down an ice slope on our decent while we were roped together. Afterwards, Sally began taking photos while I remained shaken at the thought of what could have eventuated had I not secured my position as I saw her tumble. Our disparate reactions to the same event were likely due to different levels of experience regarding risk management and adventure tourism. These discrepancies suggested that adventure tourists' personal knowledge and background may exert distinct influences on their motivational states and subsequent felt emotions.

The nature of the activity itself may also influence motivational states. Research has suggested that mountaineers may frequently experience the telic state (Houge Mackenzie et al., 2011). Certainly, many adventure activities require a narrow, goal-oriented focus which may facilitate reversals to serious (telic), self-focused (autic), and/or domination-oriented (mastery) states. A study of Arctic trekking also identified instances in which tourists evidenced rebellious (negativistic) states (Gyimothy \& Mykletun, 2004), a finding which did not emerge from the autoethnographical data in this study. In light of these findings, the current results regarding motivational state patterns in relation to guides, equipment, and the environment in mountaineering adventure tourism should be explored further across activities and individuals.

\section{Key Findings}

The current study complemented previous research that identified the positive psychological results of experiences matching or exceeding expectations (Black \& Gregersen, 1990). In contrast to these results, this study explicitly identified the negative psychological results of inconsistencies between experiences and expectations. The data presented here also supported previous research which identified trust in operators and the activity outcome as essential elements of successful adventure tourism experiences (Cloke \& Perkins, 2002). Most importantly, the current study identified: (a) psychological mechanisms underpinning mountaineering adventure tourism experiences (i.e. governing motivational states), and (b) key contingency events, such as guiding style, social interactions, weather, and equipment, which may instigate motivational reversals and emotional state changes for adventure tourists.

While positive adventure recreation experiences result from opportunities to exercise personal control over risks and feelings of competence gained through experience and the matching of challenges and personal skills (Ewert \& Hollenhorst, 1989), the current study indicated that these elements may not produce optimal adventure tourism experiences. This investigation identified that while true risk, danger, and uncertainty may optimise adventure recreation experiences, mountaineer adventure 
tourists may respond negatively to these perceptions. These findings only partially supported previous research which identified that adventure tourists seek fear and thrills with minimal exposure to actual risk (Cater, 2006). Rather than fear or instant thrills, the participants in this study sought a challenging, yet safe experience in which they felt protected from risk (i.e. a protective frame). These data suggested that further evaluation and development of psychological models informing adventure tourism research is needed, particularly with regard to mountaineering adventure tourism. These models should adequately account for psychological differences in motivational state patterns, which may vary by participant and/or activity.

Models informed by reversal theory may improve our understanding of the structure of tourists' psychological experiences and help explain: the 'adventure paradox' experienced by adventure tourists; how and why motivational state reversals occur; typical motivational and emotional patterns; and factors that will predictably enhance or diminish adventure tourists' protective frames and risk perceptions, such as those identified in this study. The paradoxical desire for perceived risk and security in adventure tourism may not be paradoxical when understood in the context of the protective frame and motivational state changes. The participant in this study did not actually seek risk, but rather a protective frame of security from which to successfully complete an activity beyond her personal skill level. Thus, the adventure 'paradox' may result from motivational state fluctuations and the presence or absence of a protective frame during an adventure tourism activity. Motivational states, such as the telic and paratelic states, dictate how positively or negatively tourists will experience events. In this investigation, a reversal theory framework helped to identify factors likely to instigate changes in tourists' motivational states, a finding which may help operators predict and plan for reversals, and react effectively to state changes. Understanding common motivational state patterns, reversal mechanisms, and their psychological structures can provide predictive information to operators and inform the development of psychological models of adventure tourism.

\section{Limitations}

It is noteworthy that the lead author's background in adventure sports, tourism, and reversal theory sensitised data analysis to issues surrounding risk management, guiding service quality, and reversal theory constructs. A true adventure tourism novice may have successfully retained a protective frame despite the unexpected events of this trip. The oft-quoted proverb 'ignorance is bliss' seemed applicable to Sally and some of the other tourists encountered on the mountain. However, given the fact that many adventure tourism offerings have skill prerequisites (mountaineering being an obvious example), this analysis of psychological mechanisms underpinning mountaineering adventure tourists' emotional experiences (including those with adventure experience) provides valuable information for researchers and operators alike. Moreover, this investigation identified important psychological aspects of mountaineering adventure tourism from a prospective, autoethnographic perspective, 
areas which require development within the adventure tourism literature (e.g. Pomfret, 2006; Weber, 2001).

An additional limitation of this study was the culturally constructed nature of the lead author's experiences. Her experiences reflected a euro-centric perspective of adventure tourism norms and expectations. The adventure operators, and participants from different backgrounds, may have experienced the events captured in the data very differently; they may have been considered the norm in this context or an integral part of the adventure experience. For example, Rocky commented at one point that it was all part of the adventure', which may reflect a more traditional notion of adventure often adopted in adventure recreation settings: the negotiation of 'real' risks and uncertainties. Thus, although the lead author's background may have enhanced data analysis of psychological concepts and provided insights regarding how tourists from euro-centric backgrounds may experience mountaineering adventure tourism, it was also limiting. Future research should consider alternative theoretical and cultural perspectives of these data and seek to incorporate researchers indigenous to the area in which the adventure tourism activity occurs to broaden the perspectives presented in this study.

\section{Implications and Future Directions}

This autoethnographic (e.g. Anderson \& Austin, 2012) investigation of mountaineering adventure tourism has a range of practical and theoretical implications. It highlighted the crucial role of guides in fostering and maintaining a 'protective frame' for clients, as conceptualised within reversal theory. In line with Weber's (2008) assertions, these findings indicated that adventure operators should consider broadening their management focus beyond physical risks to include strategies that help participants successfully encounter other types of risk (e.g. psychological), which may emerge due to heightened perceptions of physical risk. This could be achieved by: improving cross-cultural communication skills; gaining a better understanding of clients' diverse abilities, backgrounds, and expectations prior to the trip; providing sufficient skills training and safety information throughout the trip; demonstrating genuine concern and caring for clients; improving logistical organisation; providing quality equipment; and ensuring challenges can be met, or exceeded, by clients' skill levels.

This study indicated that operators should perhaps adjust their products to suit true novices. Although Beedie and Hudson (2003, p. 627) claim 'there exists something of a paradox whereby the more detailed, planned and logistically smooth an itinerary becomes the more removed the experience is from the notion of adventure', this study suggested that providing a detailed and logistically well-organised itinerary may be highly desirable for tourists. Ensuring a trip is systematically planned and managed may (a) allow guides to focus their attention on providing skill instruction, safety information, and building client trust, rather than becoming distracted by logistics; and (b) foster the protective frame necessary for clients to experience positive emotions associated with adventure. The desire for a strong 'protective frame' and a 
systematically planned experience (even if not overtly obvious) may represent one of the key differences between mountaineering adventure tourists and mountaineering adventure recreationalists.

Potential differences among mountaineer tourists and recreationalists in terms of their background and expectations (e.g. comfort, protection, fun for mountaineer adventure tourists versus hardship and personal challenge for mountaineer adventure recreationalists) may also account for these findings. Such differences could potentially contribute to poor outcomes for both tourists and operators if mountaineering recreationalists become mountaineering guides and continue to maintain 'recreational' expectations and notions of adventure in an adventure tourism setting. As anecdotal data from the current study suggested this may occur in some cases, investigations of adventure perceptions among mountaineering tourists and guides merit further consideration. Future research could compare and contrast motivational state patterns, emotional responses, and factors influencing these states among mountaineers in professional guiding, recreational, and tourism contexts. These studies could further identify potential differences among mountaineering adventure tourists, mountaineering adventure recreationalists, and mountaineering guides, as well as the implications for mountaineering tourism experiences.

\section{Conclusion}

At a theoretical level, reversal theory is a paradigm that may account for the paradoxical nature of adventure tourism and the emotional fluctuations within these experiences. By fostering a salient protective frame for clients (e.g. via developing personal skills and confidence in guides and equipment), operators may potentially reduce psychological risks, and allow physical risks to be experienced as simultaneously exciting and secure. As this has been proposed as the penultimate goal of successful adventure tourism experiences (e.g. Cater, 2006; Fletcher, 2010), it is important to develop a robust theoretical rationale of how this can be facilitated and why it does (or does not) occur. Reversal theory provides a coherent psychological account of this paradox that can provide well-defined implications for practitioners. To address potential limitations of this study, reversal theory analyses of adventure tourism experiences should be examined among larger, more diverse samples and across a broader range of guided adventure sports. Future investigations should also account for the diverse nature of mountaineer adventure tourists, in terms of background, experience, and expectations, and the influence these factors may have on motivational state patterns.

This article contributed to sport tourism literature in a number of ways. It provided a rich, emotionally nuanced autoethnography of mountaineering adventure tourism, in response to calls for investigations of tourists' subjective experiences - particularly in mountaineering settings (e.g. Pomfret, 2006; Weber, 2001). An alternative theoretical explanation of psychological mechanisms governing adventure tourists' experiences was also presented. A reversal theory framework was used to explain how the paradoxical experience of perceived risk and security may occur in adventure 
tourism, and to identify underlying mechanisms governing emotional fluctuations during adventure activities. This innovative framework for understanding tourists' motivations, emotions, and experiences may strengthen future sport tourism investigations. Above all, the value of autoethnography in uncovering otherwise overlooked insights and illuminating unique perspectives on subjective experiences was highlighted. Specific factors influencing tourists' subjective experiences and perceptions of experience quality were revealed by examining autoethnographical data with an established psychological theory. A substantial review of autoethnographic leisure research found that autoethnographical investigations provided compelling and valuable analytical insights which primarily resulted from the unique nature of this methodology (Anderson \& Austin, 2012). The current study reinforced these findings by underscoring the value of autoethnographic research in adventure settings, particularly in conjunction with established psychological theory. Autoethnography is recommended as a fruitful avenue through which to enhance the adventure tourism discourse and our understanding of idiosyncratic tourism experiences.

\section{Note}

[1] All names are pseudonyms.

\section{References}

Anderson, L. (2006) Analytic autoethnography, Journal of Contemporary Ethnography, 35, pp. 373-394.

Anderson, L. \& Austin, M. (2012) Auto-ethnography in leisure studies, Leisure Studies, 31(2), pp. 131-146.

Apter, M. J. (1982) The Experience of Motivation: The Theory of Psychological Reversals (London: Academic Press).

Apter, M. J. (1992) The Dangerous Edge: The Psychology of Excitement (New York: Free Press).

Apter, M. J. (1993) Phenomenological frames and the paradoxes of experience, in: J. H. Kerr, S. J. Murgatroyd \& M. J. Apter (Eds.) Advances in Reversal Theory, pp. 27-39 (Amsterdam: Swets \& Zeitlinger).

Apter, M. J. (ed.) (2001) Motivational Styles in Everyday Life: A Guide to Reversal Theory (Washington, DC: American Psychological Association).

Arnould, E. \& Price, L. (1993) River magic: Extraordinary experience and the extended service encounter, Journal of Consumer Research, 20(1), pp. 24-45.

Arnould, E., Price, L. \& Tierney, P. (1998) Communicative staging of the wilderness servicescape, The Service Industries Journal, 18(3), pp. 90-115.

Arnould, E., Price, L. \& Otnes, C. (1999) Making magic consumption: A study of white- water river rafting, Journal of Contemporary Ethnography, 28(1), pp. 33-68.

Beedie, P. (2003) Mountain guiding and adventure tourism: Reflections on the choreography of the experience, Leisure Studies, 22(2), pp. 147-167.

Beedie, P. \& Hudson, S. (2003) Emergence of mountain-based adventure tourism, Annals of Tourism Research, 30(3), pp. 625-643.

Bentley, T. A. \& Page, S. (2001) Scoping the extent of adventure tourism accidents, Annals of Tourism Research, 28(3), pp. 705-726.

Black, J. S. \& Gregersen, H. B. (1990) Expectations, satisfaction, and intention to leave of American expatriate managers in Japan, International Journal of Intercultural Relations, 14(4), pp. 485-506. 
Cater, C. I. (2006) Playing with risk? Participant perceptions of risk and management Implications in adventure tourism, Tourism Management, 27(2), pp. 317-325.

Cloke, P. \& Perkins, H. C. (2002) Commodification and adventure in New Zealand tourism, Current Issues in Tourism, 5(6), pp. 521-549.

Csikszentmihalyi, M. (1975) Beyond Boredom and Anxiety (San Francisco, CA: Jossey-Bass Publishers).

Csikszentmihalyi, M. \& Csikszentmihalyi, I. S. (1990) Adventure and the flow experience, in: J. C. Miles \& S. Priest (Eds.) Adventure Education, pp. 149-155 (State College, PA: Venture Publishing).

Davis-Berman, J. \& Berman, D. (2002) Risk and anxiety in adventure programming, Journal of Experiential Education, 25(2), pp. 305-310.

Ellis, M. J. (1973) Why People Play (Englewood Cliffs, NJ: Prentice-Hall).

Ewert, A. \& Hollenhorst, S. (1989) Testing the adventure recreation model: Empirical support for a model of risk recreation participation, Journal of Leisure Research, 21(2), pp. 124-139.

Fletcher, R. (2010) The emperor's new adventure: Public secrecy and the paradox of adventure tourism, Journal of Contemporary Ethnography, 39(1), pp. 6-33.

Frey, K. P. (1999) Reversal theory: Basic concepts, in J. H. Kerr (Ed.) Experiencing Sport: Reversal Theory, pp. 3-17 (New York: John Wiley \& Sons).

Gyimothy, S. \& Mykletun, R. J. (2004) Play in adventure tourism: The case of arctic trekking, Annals of Tourism Research, 31(4), pp. 855-878.

Holyfield, L. (1999) Manufacturing adventure: The buying and selling of emotions, Journal of Contemporary Ethnography, 28, pp. 3-32.

Holyfield, L., Jonas, L. \& Zajicek, A. (2005) Adventure without risk is like Disneyland, in: S. Lyng (Ed.) Edgework: The Sociology of Risk-Taking, pp. 173-185 (New York: Routledge).

Houge Mackenzie, S., Hodge, K. \& Boyes, M. (2011) Expanding the flow model in adventure activities: A reversal theory perspective, Journal of Leisure Research, 43(4), pp. 519-544.

Huayna Potosí (n.d.). Refugio Huayna Potosí. Available at http://www.huayna-potosi.com/ mountaineering.html\#huayna (accessed 3 December 2010).

Huayna Potosi: SummitPost (n.d.). SummitPost.Org Available at http://www.summitpost.org/ huayna-potosi/150675 (accessed 3 December 2010).

Hudson, S. (Ed.). (2003) Preface, in: Sport and Adventure Tourism, pp. xvii-xix (New York: The Haworth Press).

Jonas, L. M., Stewart, W. P. \& Larkin, K. W. (2003) Encountering Heidi: Audiences for a wilderness adventurer identity, Journal of Contemporary Ethnography, 32(4), pp. 403-431.

Jones, C., Hollenhorst, S. \& Perna, F. (2003) An empirical comparison of the Four Channel Flow Model and Adventure Experience Paradigm, Leisure Sciences, 25(1), pp. 17-31.

Kahn, C. A. (2009) Go play in traffic: Skating, gender, and urban context, Qualitative Inquiry, 15(6), pp. 1084-1102.

Kerr, J. H. (1991) Arousal seeking in risk sport participants, Personality and Individual Differences, 12(6), pp. 613-616.

Kerr, J. H. (ed.) (1999) Experiencing Sport: Reversal Theory (New York: John Wiley \& Sons).

Kerr, J. H. (2001) Sport and exercise, in M. J. Apter (Ed.) Motivational Styles in Everyday Life: A Guide to Reversal Theory, pp. 187-214 (Washington, DC: American Psychological Association).

Kerr, J. H. (2007) Sudden withdrawal from skydiving: A case study informed by reversal theory's concept of protective frames, Journal of Applied Sport Psychology, 19(3), pp. 337-351.

Kidder, J. L. (2006) Bike messengers and the really real: Effervescence, reflexivity, and postmodern identity, Symbolic Interaction, 29(3), pp. 349-371.

Loeffler, T. A. (2004) A photo elicitation study of the meanings of outdoor adventure experiences, Journal of Leisure Research, 36(4), pp. 536-556.

Lyng, S. (1990) Edgework: A social psychological analysis of voluntary risk taking, The American Journal of Sociology, 95(4), pp. 851-886. 
Martin, P. \& Priest, S. (1986) Understanding the adventure experience, Journal of Adventure Education, 3(1), pp. 18-21.

Merriam-Webster (1994) Merriam-Webster's Dictionary of English Usage (Springfield, MA: MerriamWebster).

Mortlock, C. (1984) The Adventure Alternative (Cumbria, UK: Cicerone Press).

O'Connell, K. A., Potocky, M., Cook, M. R. \& Gerkovich, M. M. (1991) Metamotivational State Interview and Coding Schedule Instruction Manual (Kansas City, MO: Midwest Research Institute).

Palmer, C. (2004) Death, danger, and the selling of risk in adventure sport, in: B. Wheaton (Ed.) Understanding Lifestyle Sports, pp. 55-69 (New York: Routledge).

Patterson, I. (2002) Baby boomers and adventure tourism: The importance of marketing the leisure experience, World Leisure Journal, 44(2), pp. 4-10.

Pomfret, G. (2006) Mountaineering adventure tourists: A conceptual framework for research, Tourism Management, 27(1), pp. 113-123.

Priest, S. \& Carpenter, G. (1993) Changes in perceived risk and competence during adventurous leisure experiences, Journal of Applied Recreation Research, 18(1), pp. 51-71.

Snow, D., Morrill, C. \& Anderson, L. (2003) Elaborating analytical ethnography: Linking fieldwork and theory, Ethnography, 4(2), pp. 181-200.

Walle, A. (1997) Pursuing risk or insight: Marketing adventures, Annals of Tourism Research, 24(2), pp. 265-282.

Weber, K. (2001) Outdoor adventure tourism: A review of research approaches, Annals of Tourism Research, 28(2), pp. 360-377.

Weber, K. (2008) Outdoor adventure tourism: A review of research approaches, in M. Weed (Ed.) Sport \& Tourism: A Reader, pp. 57-70 (New York: Routledge).

Xola Consulting (2010, August) Adventure tourism market report. Available at Xola Consulting Industry Research Reports Online: http://www.xolaconsulting.com/Adventure-Market-2010. pdf (accessed 9 October 2010). 